\title{
A survey of tumors affecting cattle, buffaloes and sheep, in El-Dakahlyia Governorate
}

\author{
Inas Moharram ${ }^{1}$, Walaa F. Awadin ${ }^{1}$ Mohammed Fawzy Hamed ${ }^{1}$, Salem, M. G. ${ }^{2}$, Mosbah, E. ${ }^{2}$ \\ ${ }^{1}$ Department of Pathology, Fac. Vet. Med, Mansoura University \\ ${ }^{2}$ Department of Surgery, Anesthesiology and Radiology, Mansoura University, Mansoura, Egypt
}

\begin{abstract}
In a 2-year survey of tumors occurring in ruminants reared in El-Dakahlyia Governorate, Egypt during the period from October 2016 to October 2018. 66 tumor masses were collected: 60 from cattle, 2 from buffaloes and 4 from sheep. According to histopathology of cattle tumors, 15 neoplasms were diagnosed as cutaneous papilloma, 5 neoplasms were diagnosed as cutaneous fibropapillomas, 25 neoplasms were diagnosed as squamous-cell carcinoma (SCC) of the eye; 8 neoplasms were diagnosed as SCC of perineum, 1 neoplasm was diagnosed as SCC in skin of muzzle, 2 neoplasms were diagnosed as epulis in dental pad, 2 neoplasms were diagnosed as vaginal leiomyoma, 1 neoplasm was diagnosed as fibroma and 1 neoplasm was diagnosed as liposarcoma. Histopathology of buffalo tumors revealed SCC in head skin ( 1 case) and buccal cavity (1 case). Histopathology of sheep tumors revealed SCC in skin under the tail ( 2 cases), skin of groin ( 1 case) and skin of abdomen ( 1 case). In conclusion, cattle (60/66) were more susceptible to tumors than buffaloes $(2 / 66)$ and sheep (4/66). Females accounted for a higher percentage of the neoplasms (47/66) than males (19/66). Adult animals aged above 2 years were more frequently affected than young. The occurrence of epithelial tumors $(60 / 66)$ was greater than the mesenchymal tumors (6/66). The most common epithelial tumors were ocular SCC and cutaneous papilloma. Number of malignant tumors $(41 / 66)$ was higher than number of benign tumors $(25 / 66)$. Variable degrees of bovine SCC differentiation were detected. Meanwhile ovine SCC appeared only well differentiated.
\end{abstract}

Keywords: Tumors, cattle, Buffaloes, sheep, Histopathology

\section{INTRODUCTION}

The incidence of neoplasm in ruminants was previously studied by Jelinek and Tachezy, (2005) and Valentine, (2006). Different types of tumors were demonstrated in domestic animals such as squamous cell carcinoma (SCC) (Yager et al., 1993 and Wilcock, 1993), fibroma (Goldshmidt \& Hendrick, 2002), lymphosarcoma (Moulton, 1990; Jones et al., 1996), Haemangiosarcoma (Maddox and Evens, 1981) and liposarcoma (Enterline, 1960).

In a survey study on 202 tumors collected from different farm animals in different localities of Egypt (Assiut, El-Menia and Sohag), the diagnosis was: fibropapilloma (54.4\%), fibroma (8.4\%), SCC (1.9\%), lymphosarcoma (0.9\%), haemangiosarcoma (0.9\%), Liposarcoma (0.4\%) and malignant teratoma (0.4\%) (Hassanein and Mahmoud, 2009). Buccal SCC, hemangioma and rectal leiomyoma were previously reported in buffaloes by Awadin and Mosbah, (2013). Four cases of SCC were observed in the eye lid of cattle and lips of sheep (Hassanein and Mahmoud, 2009).

The etiology of the disease was multifactorial but it was suggested that predisposition to the tumor may be hereditary (Radostits et al., 1994). Some classes of cattle, especially
Herford, are noted for their great occurrence of carcinomas when retained in subtropical areas, but these carcinomas originated not from skin but from the ocular epithelium (Spradbrow and Hoffman, 1980). Sheep has carcinomas actually related to exposure to sun light on areas of integument free from fleece, mainly the ears and muzzle (Lioyd, 1961) and the perineal area (Vandegraaf, 1976).

Lengthy exposure to sunlight (ultraviolet light) also appears to be a driving force for occurrence of the disease (Anderson and Badzioch, 1991). At least 6 different types of bovine papillomavirus (BPV) have been identified; BPV1; BPV2 and BPV5 cause cutaneous fibropapilloma, while BPV3, 4, 6 cause squamous papillomas of the skin and esophagus (Yager et al., 1993 and Goldshmidt \& Hendrick, 2002).

Spradbrow et al., (1987) suggested that cutaneous tumours may be the outcome of a complex series of interactions of the epidermal and adenexal cells with papillomavirus, ultraviolet rays and other factors such as immunosuppressive or photosensitizing agents. Solar radiation is predisposing factor in SCC in the ears and nose of white cats, on the perineum and ears of Angora goats in Africa and on the eyelids of cattle. Mechanical irritations, injuries and burns can also lead to SCC (Weiss and Frese, 1974). 
However, the exact etiology of oral squamous cell carcinoma was still unknown but some researchers reported that predisposing factors for oral cancer can be usually classified into several categories (El-Mofty et al. 2009) including over exposure to UV rays in combination with managemental and environmental factors, viral infections in addition to genetic factors, feeding behaviors and immunodeficiency status (Goldschmidt and Hendrick, 2002).

The present work described histopathology of 66 tumor masses collected from cattle, sheep and buffaloes in ElDakahlyia Governorate during the period from October 2016 to October 2018.

\section{MATERIALS AND METHODS}

\section{Animals}

Cattle, buffaloes and sheep reared in El-Dakahlyia private farms and those presented to Mansoura Veterinary Teaching Hospital suspected to be affected with neoplesia were clinically examined during the period from October 2016 to October 2018. A total number of sixty six tumor masses were detected in 60 cattle, 2 buffaloes and 4 sheep of different breeds, ages and sexes. Numbers, sex, age, and locations of the lesions from which the samples had been excised were shown in Table 1.

\section{Tissue samples}

Representative tissue samples were collected and submitted to the Department of Veterinary Pathology, Faculty of Veterinary Medicine, Mansoura University by the following methods:

Cutaneous warts and fibropapillomata were benign and not admitted for surgical removal. Only biopsies were obtained under the effect of xylazine $\mathrm{HCl} 2 \%$ at dose $0.05 \mathrm{mg} \backslash$ kg i. $m$.inj. (XYLAJECT, ADWIA, A.R.E)

For surgical removal of cutaneous masses, cattle and buffaloes were operated under the effect of xylazine $\mathrm{HCl} 2 \%$ in addition to infiltration analgesia using lidocaine $\mathrm{HCl} 2 \%$ (Debocaine, El-nasr Pharma. chemicals Co. for Al-Debeiky Pharma-A.R.E.). For surgical removal of masses from vagina and perineum, epidural analgesia was performed by injection of combination from xylazine $\mathrm{HCL} 0.03 \mathrm{mg} \backslash \mathrm{kg}$ and lidocaine $\mathrm{HCL} 0.22 \mathrm{mg} \backslash \mathrm{kg}$. For removal of masses in abdomen and under the tail in sheep, the animals were sedated with xylazine $\mathrm{HCL} 0.03 \mathrm{mg} \backslash \mathrm{kg}$ and then circular infiltration by lidocaine $\mathrm{HCL} 1 \%$

3- For surgical removal of ocular SCCs, cattle were sedated with xylazine $\mathrm{HCl} 2 \%$ and Retropalpar nerve block was performed in addition to infiltration analgesia around upper and lower eye lids. Extirpation of eye ball was performed according to Weaver et al., 2018. Penicillin Procaine 22000 I.U $\backslash \mathrm{kg}$ (Norocillin, Norebrock, Holand) and analgesic flunixin meglumine (Finadyne, Schering, Germany) at the rate of $2.2 \mathrm{mg} / \mathrm{kg}$ body weight were administered intramuscularly, daily for three consecutive days.

\section{Histopathological study}

Formalin fixed tissue specimens were processed in ascending grades of ethyl alcohol (80\%, 90\% and 100\%), cleared in xylene and embedded in paraffin wax until the time of diagnostic application. Sections were cut at $5 \mu \mathrm{m}$ thickness, picked up on glass slides, dried, deparafinized with xylene and rehydrated with descending grades of ethyl alcohol, washed and stained with H\&E according to Bancroft and Gamble, (2007). The stained sections were dehydrated in absolute ethyl alcohol, cleared in xylene and mounted with MountQuick liquid cover glass medium to the surface of the slides. Sections were examined under light microscope and digital images were captured.

\section{RESULTS}

\section{1-Cutaneous papillomatosis and fibropapillomatosis}

\section{A-Gross appearance}

Cutaneous papillomatosis were detected in 15 cattle ranging between 5 months and 3 years, meanwhile, fibropapilloma were detected in 5 cattle ranging between 8 months to 1 year. The lesions appeared dry and horny either nodular or cauliflower, solitary or multiple in skin of head, around eyes, neck, back, shoulder, axilla and all over the body. Size of warts varied from 1-6 $\mathrm{cm}^{3}$ and color was grayish white to black (Fig. 1).

\section{B-Microscopic appearance}

Histological characteristic of cutaneous papillomatosis was hyperkeratosis, acanthosis with elongated rete pegs in a fibrovascular stroma. Moreover, hypergranulosis (proliferation of granulocytes) with hydropic degeneration of granulocytes were seen in the stratum granulosum layer. Koilocytes characterized by vacuolated cytoplasm, some of them contained small distorted nuclei with dense chromatin arranged in small groups were often present. Pigmentation was also observed. Cutaneous fibropapilloma was grossly indistinguishable from papilloma. Microscopically, it was similar to papilloma however stroma showed hypercellularity of fibroblasts forming whorls around blood vessels (Fig. 2).

\section{2- Squamous cell carcinoma (SCC)}

\section{A- Gross appearance}


SCCs were diagnosed in 34 cattle affecting eyes in 25 cattle aged 2 to 10 years with secondary metastasis to retropharyngeal lymph node in 2 cases. Ocular SCCs appeared nodular and hemorrhagic with or without purulent discharge or cauliflower like and congested. SCCs were diagnosed in perineum of 8 cattle aged 9 years and skin of muzzle in 1 case aged 7 to 9 years. SCCs were diagnosed in 2 buffaloes involving facial skin of a 3 years old buffalo and oral mucosa of an 8 years old buffalo cow. Buccal SCC tumor appeared as a large $(12 \mathrm{~cm} \times 7 \mathrm{~cm})$ ulcerated rectangular mass protruding from the mouth hindering feeding of the animal. In sheep, SCCs affected skin under tail (2 cases), skin of groin (1 case) and abdomen (1 case). All cutaneous SCCs were often red, elevated, fungating, scaling thickened patch with ulcerated surface and irregular borders. Other symptoms included sores, ulcers, discoloring and hyperkeratosis (Fig. 3).

\section{B-Microscopic appearance}

Histological characteristic of bovine SCC was ranged from well differentiated to poorly differentiated invasive squamous epithelium associated with inflammation. In well differentiated SCC, cell nests or keratin pearls resulting from downward infiltration of malignant epidermal keratinocytes were observed. The neoplastic cells mostly similar those of normal stratum spinosum showing clear spinous differentiation with enlarged, hyperchromatic and vesicular nuclei and one or multiple very prominent nucleoli. Vacuolation of neoplastic cells was seen. Numerous typical and atypical mitotic figures were recognized in higher magnification. Superficial part of SCC showed ulceration and inflammatory cellular exudation. Polymorphnuclear cells and lymphocytic cells infiltration were noticed. Acantholytic SCC was also diagnosed and showed pseudoglandular structures which extended into the dermis with acantholytic clefts created in the center of these structures. Heavy invasion of inflammatory cells among the islands were also present. In illdifferentiated SCC, typical cell nests were hardly recognized because of pleomorphism, anaplasia, poor spinous differentiation of neoplastic cells and few mitotic figures. Individually keratinized cells were observed (Fig. 4).

\section{3- Epulis}

\section{A-Macroscopic appearance}

Macroscopically epulis was detected as a localized mass of tissue on the gum in 2 calves of 8 months and 2 years old. The gingival hyperplasia of about $4 \mathrm{~cm} \times 2 \mathrm{~cm}$ length and $5 \mathrm{~cm} \times 3 \mathrm{~cm}$ length were situated in the rostral maxilla and had a wide base of implantation, affecting part of the alveolar ridge and palate. Tumorous masses had an irregular surface, similar to a cauliflower, and bleeding ulcerations. Despite the large size of the masses, they did not obstruct the airway and allowed the calf to suckle (Fig. 5).

\section{B-Microscopic appearance}

Microscopically, fibromatous epulis was diagnosed characterized by highly collagenous matrix with moderate few lymphocytic cells infiltration (Fig. 5).

\section{4-Vaginal leiomyoma}

\section{A-Macroscopic appearance}

Macroscopically, vaginal leiomyoma was detected in one 4 years- old cow. The examination of the vagina revealed a round, fleshy, nodular vaginal mass of approximately $10 \mathrm{~cm}$ diameter protruding from vulva (Fig. 6).

\section{B-Microscopic appearance}

Neoplastic tissue showed noticeable hypercellularity of smooth muscle cells implanted in a connective tissue stroma. The cytoplasm was eosinophilic homogeneous and sometimes finely vacuolated. With conspicuous, small, multiple nucleoli, nucleus had elongated shape with mild irregularity in borders. Angiogenesis was remarkable with increased number of dilated blood vessels (Fig. 6).

\section{5-Liposarcoma}

\section{A- Macroscopic appearance}

Liposarcoma was detected grossly as a very hard lemon sized subcutaneous mass in neck of a one year old cow heifer.

\section{B-Microscopic appearance}

Histopathologically, the lesion contained compactly cellular lobules divided by a variably compact fibrovascular stroma. Mature adipocytes showed cellular atypia and marked variations in size and shape. Neoplastic cells were spindle or stellate or polygonal in shape and characterized by presence of marked cellular atypia and numerous mitoses. Cells showed large, round or oval or irregular shaped nuclei with coarsely clumped to vesicular chromatin, 1-2 prominent nucleoli and some atypical mitotic figures. Tumor giant cells were evident.

\section{6- Fibroma}

\section{A-Macroscopic appearance}

Fibroma was grossly described as a submandibular rounded nodule in 8 years old cow.

\section{B-Microscopic appearance}

Microscopical examination showed fibroblasts running in various directions forming whorls around blood vessels.

Collectively, cattle (60 cases) were more affected with tumors than buffaloes ( 2 cases) and sheep (4 cases). Females accounted for a higher percentage of the neoplasms (47/66) than males (19/66). Adult animals aged above 2 years were more frequently affected than young. The occurrence of 
epithelial tumors $(60 / 66)$ was greater than the mesenchymal tumors (6/66). The most common epithelial tumors were SCC (40/66) and cutaneous papilloma \& fibropapilloma (20/66). 34 cases out of 66 neoplasms were originated from skin. The
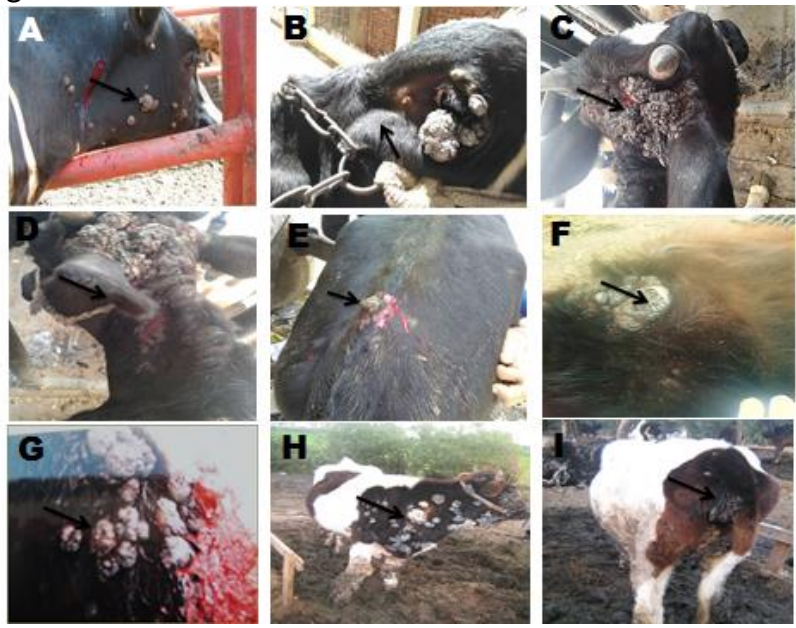

Fig.1: Gross pictures of cattle affected with cutaneous papilloma in face\&neck (A), around eye (B), head (C), shoulder (D), back (E\&F), allover body ( G-I) either solitary or multiple, nodular or cauliflower (arrows).
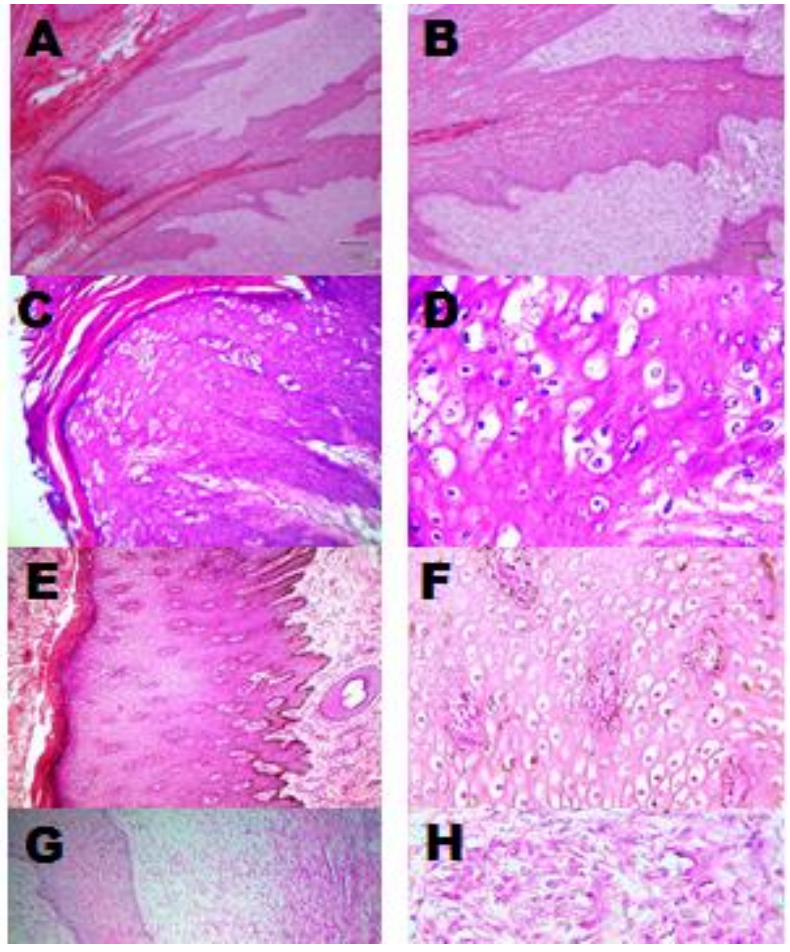

Figure 2. Microscopic pictures of cutaneous papilloma showing prominent hyperkeratosis, acanthosis, elongated rete-pegs ( $r$ ) with intact basement membrane (black arrow) and underlined with fibrovascular stroma (s) (A\&B). Hydropic degeneration of epidermal cells is demonstrated (C-F). Microscopic picture of fibropapilloma demonstrates fibroma arises from stroma characterized by hypercellularity of fibroblasts forming whorls (red arrows) around blood vessels (G\&H). H\&E, X: $100(A, C, E, G)$ and X: 400 (B,D,F,H). 

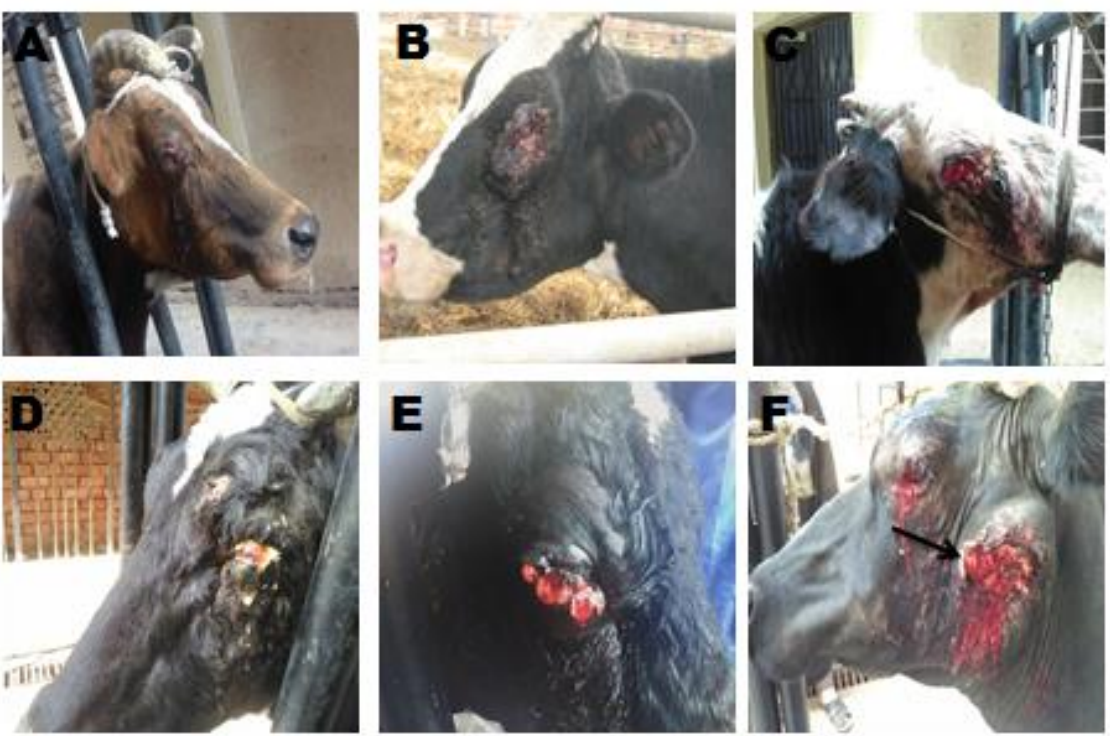

Fig. 3: Gross pictures of cattle affected with ocular SCC appeared nodular, ulcerated and hemorrhagic in (A-C) accompanied with purulent discharge in (D) or cauliflower like and congested (E) and metastasize to retropharyngeal lymph node (F) (arrow).
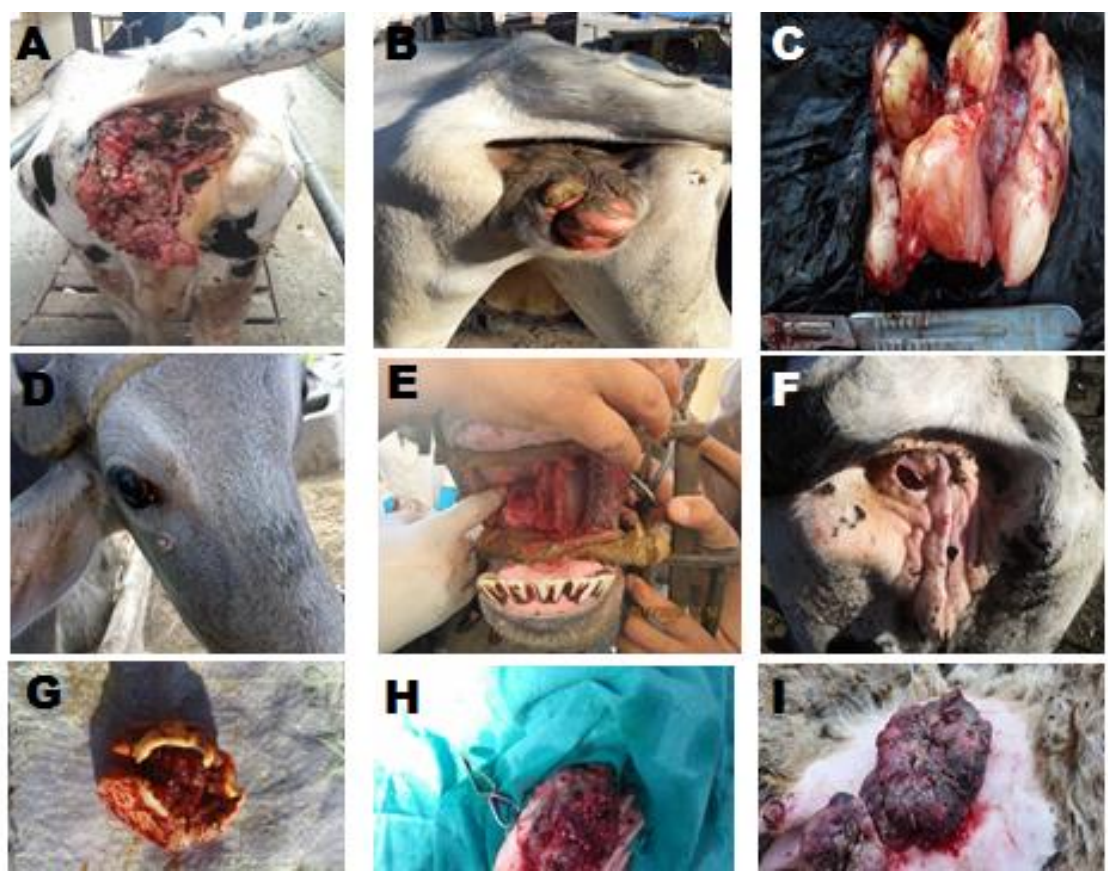

Figure 4. Gross pictures of SCC affecting perineum in cattle before surgical removal (A,B,D) and shows tumorous mass after surgical removal (C\&E). SCC appears as a small ulcerated nodule in facial skin of a buffalo cow (F). SCC appears as a large ulcerated irregular mass originated from right cheek mucosa in a buffalo cow (G). Macroscopic pictures of SCC in a sheep before surgical excision in skin under tail (H) and abdomen (I) appears as red, elevated, fungating, scaling thickened patch with ulcerated surface and irregular borders. 

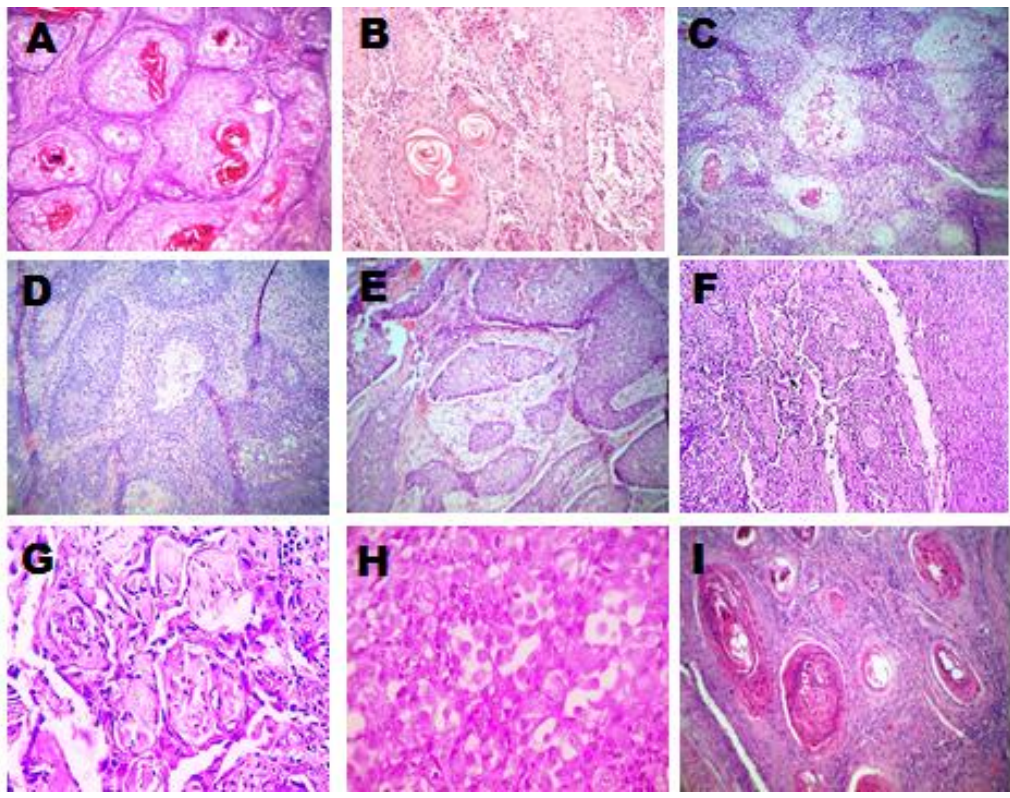

Figure 5. Microscopic pictures of bovine SCC with variable degrees of differentiation (A-H). Well differentiated SCC showing typical keratin pearls characterized by pleomorphism, hyperchromatism of the nuclei with large prominent nucleoli, clear spinous differentiation of the neoplastic cells, vaculation of neoplastic cells, and numerous mitotic figures (A\&B). Acantholytic SCC showing prominent gland-like spaces which contains of acantholytic cellular components (C\&D). III- differentiated SCC showing hardly recognized typical cell nests because of pleomorphism, anaplasia and poor spinous differentiation of neoplastic cells $(E-H)$. Well differentiated SCC showing typical keratin pearls was diagnosed in 2 sheep affected with SCC in skin of tail (I). H\&E, X: 100 (A-E, G,I), X:400 (F\&H).
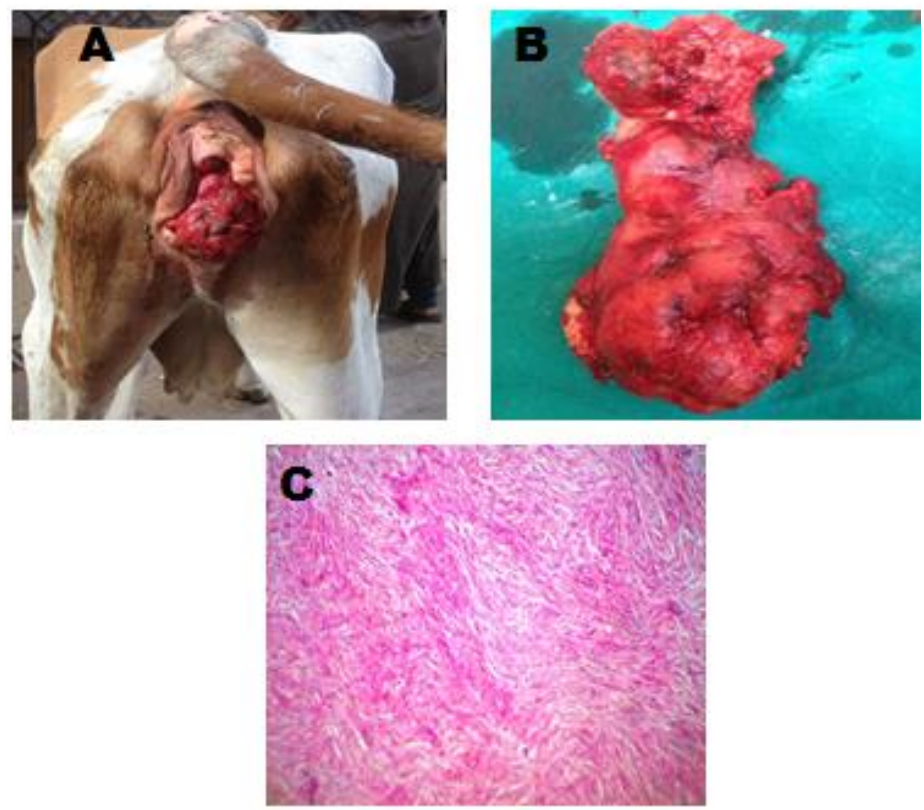

Figure 6. Gross pictures of vaginal leiomyoma in a cow before and after surgical removal (A\&B). Microscopic examination of neoplastic tissue shows marked hypercellularity of smooth muscle cells embedded in a connective tissue stroma. The cytoplasm was eosinophilic homogeneous and smooth muscle bundles are running in variable directions (C). 

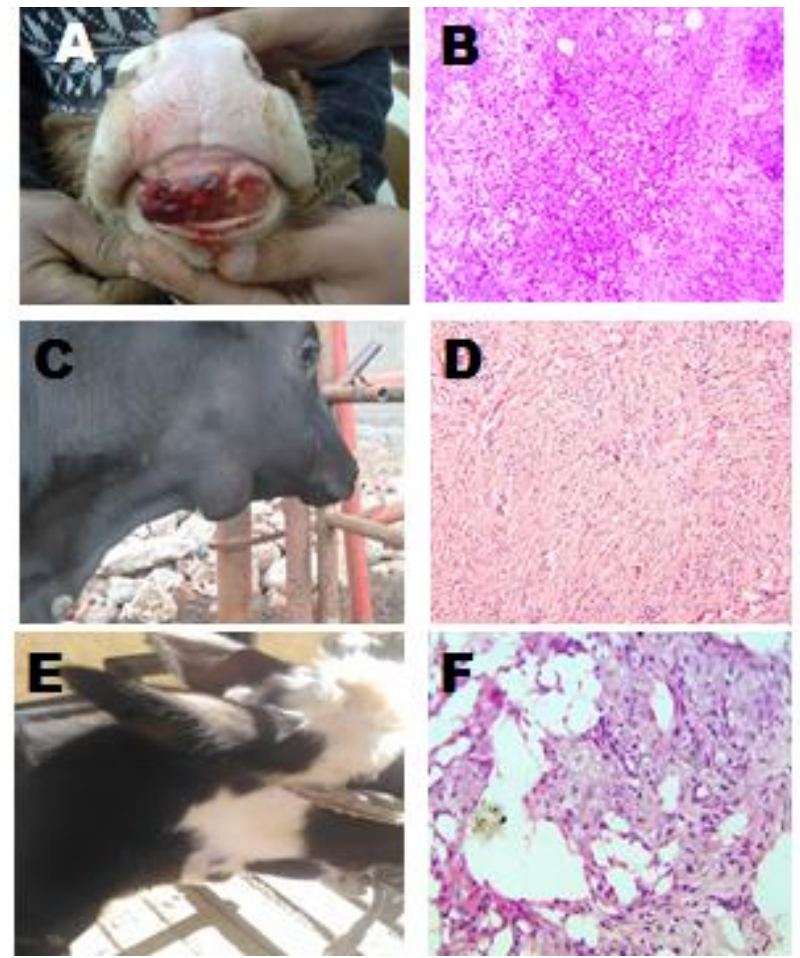

Figure 7. Gross and microscopic pictures of fibromatous epulis in a bovine calf (A\&B). Gross and microscopic pictures of fibroma in a cow (C\&D). Gross and microscopic pictures of liposarcoma in 1 y old bovine calf (E\&F).

Table 1: Tumor description in different cattle, buffaloes and sheep

\begin{tabular}{|c|c|c|c|c|c|c|c|}
\hline \multirow[t]{2}{*}{ Tumors } & \multirow[t]{2}{*}{ Species } & \multirow[t]{2}{*}{ Numbers } & \multirow[t]{2}{*}{ Location } & \multicolumn{2}{|l|}{ Sex } & \multirow[t]{2}{*}{ Age } & \multirow[t]{2}{*}{ Mean age } \\
\hline & & & & $\mathrm{F}$ & M & & \\
\hline $\begin{array}{l}\text { Cutaneous } \\
\text { papillomatosis }\end{array}$ & Cattle & 15 & $\begin{array}{l}\text { Skin of head, around eyes, neck, } \\
\text { back, shoulder, axilla and all over }\end{array}$ & 13 & 2 & $5 \mathrm{~m}$ to $3 y$ & $2 y$ \\
\hline $\begin{array}{l}\text { Cutaneous } \\
\text { fibropapilloma }\end{array}$ & Cattle & 5 & the body & 4 & 1 & $8 \mathrm{~m}$ to $1 \mathrm{y}$ & $1 y$ \\
\hline \multirow[t]{3}{*}{ SCC } & \multirow[t]{3}{*}{ Cattle } & 25 & Eye & 10 & 15 & $2-10 y$ & \multirow[t]{3}{*}{$5 y$} \\
\hline & & 1 & skin of muzzle & 1 & - & $9 y$ & \\
\hline & & 8 & perineum & 8 & - & $7-9 y$ & \\
\hline \multirow[t]{2}{*}{ SCC } & \multirow[t]{2}{*}{ buffalo } & 1 & Skin of face & 1 & - & \multirow{2}{*}{\multicolumn{2}{|c|}{$\begin{array}{l}3 y \\
8 y\end{array}$}} \\
\hline & & 1 & buccal cavity & 1 & - & & \\
\hline \multirow[t]{3}{*}{ SCC } & \multirow[t]{3}{*}{ sheep } & 2 & skin under tail & 2 & - & \multirow{3}{*}{$\begin{array}{l}1.5,2 y, 2 y \\
3 y\end{array}$} & \multirow[t]{8}{*}{$2 y$} \\
\hline & & 1 & Skin of groin & 1 & & & \\
\hline & & 1 & Skin of abdomen & 1 & & & \\
\hline Epulis & Cattle & 2 & gum & 1 & 1 & \multirow{4}{*}{$\begin{array}{l}8 m \& 2 y \\
4 y \\
6 y \\
1 y\end{array}$} & \\
\hline Leiomyoma & Cattle & 2 & vagina & 2 & - & & \\
\hline Fibroma & Cattle & 1 & Submandibular space & 1 & - & & \\
\hline Liposarcoma & Cattle & 1 & neck & 1 & - & & \\
\hline Total & & 66 & & 47 & 19 & & \\
\hline
\end{tabular}

\section{DISCUSSION}

The occurrence of tumors in ruminants was moderately increasing (66 cases collected in a 2 years survey) which decrease the animals productivity. Cattle were more susceptible to tumors than buffaloes and sheep. Cattle occupied the next place after canine for occurrence of all tumors (Marosfoi et al., 2009). Shruthi et al., (2018) 
mentioned that the occurrence of tumors was greater in cattle (78.95\%) than in buffaloes (21.05\%).

Furthermore, the incidence of epithelial tumors $(60 / 66)$ in our records was greater than the mesenchymal tumors $(6 / 66)$. Similar results were mentioned by Shruthi et al., (2018). Neoplasm affecting skin and appendages form a chief constituent of all tumours in ruminant animals (Goldschmidt and Hendrick, 2002). Our results showed that 34 cases out of 66 neoplasms were originated from skin. Similar results were obtained by (Hassanein and Mahmoud, 2009) in a survey study conducted in different localities of Egypt (Assiut, ElMenia and Sohag). In contrary to, Plummer (1956) and Dukes et al., (1982) who observed the great occurrence of mesenchymal tumors and lymphosarcoma found to be the most common tumor.

Among the skin neoplasm, bovine cutaneous papillomatosis and SCC are commonly diagnosed and economically important neoplasms in large animals (Meuten 2002; Ozsoy et al., 2001; Tan et al., 2012). The most common tumors in our findings were SCC (40/66), cutaneous papilloma and fibropapilloma (20/66). In agreement with Goldschmidt and Hendrick (2002); Kohlirn et al. (2008) who showed that, SCCs were the most common tumor followed by papillomas. Hassanein and Mahmoud, (2009) found that fibropapilloma in cattle represent $54.4 \%$ of all neoplasm. The most common SCCs in our records affected eyes (25/40 cases). Kohlirn and Mashadi (2008); Sivaseelan et al., (2008) showed that SCC was the most commonly occurring neoplasm affecting bovine eye. The most common areas affected are limbus (junction of the cornea and the sclera), third eyelid, and on the upper and lower eyelid margins primarily at mucocutaneous junctions (Goldschmidt and Hendrick, 2002). The malignant tendency of this disease makes early recognition critical.

In buffaloes, there were reports of SCC of eyes (Sivaseelan et al., 2008) and skin at the dorsal area of neck (Kohlirn and Mashadi 2008) and involving three unusual sites in cattle viz. right ischeorectal fossa, left vulval labium and right thoracic skin (Fazili et al., 2008). Besides ocular, SCCs were detected also in skin of muzzle and perineum in cattle. SCCs were detected in facial skin and buccal cavity from 2 buffaloes. Buccal SCC was previously reported in buffalo by (Awadin and Mosbah, 2013). SCCs were detected in skin under tail, groin and abdomen from 4 sheep. In sheep, high prevalence of SCC in Australia and South Africa was attributed to increased exposure of the perineum to solar radiation following tail docking to reduce the incidence of cutaneous myiasis (Hawkins et al., 1981; Tustin et al., 1982). Although SCC occurred on other parts of the goat, the perineum was the most common site as previously reported by Radostits et al., (1994); Baipoledi (2001). In addition to shape, size, posture of the tail and lack of pigmentation of the underside of the tail, it was highly likely that solar radiation plays a role in the predisposition to perineal SCC (Baipoledi 2001).

Microscopically, variable degrees of bovine SCC differentiation were detected. Meanwhile, 4 cases of ovine SCC appeared only well differentiated. Acantholytic SCC was differentiated from ordinary SCC and its histopathological evaluation was very similar to those reported by Kiani et al., (2010) affecting perineum of a female Holstein cow.

Vaginal leiomyoma are benign mesenchymal neoplasm of the vaginal wall that originated from smooth muscle. Leiomyomas are the greatest usually encountered tumors of the female reproductive system in almost all domestic species (Sharma et al., 2011). Only one case of vaginal leiomyoma was reported in a 4 years- old cow. Grossly, leiomyoma can reach up to $10-12 \mathrm{~cm}$ in diameter without being invasive. Initially, when the tumor is small it has a fleshy consistency then becomes firm or even hard as it develops due to stromal connective tissue (Meuten, 2002). In most cases, the leiomyoma projects like a nodular tumor into the uterine, vaginal or cervical lumen (Kennedy and Miller, 1993). Leiomyoma of vagina may interfere with reproductive function. If large enough they may obstruct vaginal passage (Musal et al., 2007).

Liposarcoma are infrequent tumor in ruminants animals, but have been described to happen in several species (Goldschmidt and Hendrick 2002). Among domesticated animals, liposarcoma has been most regularly occurred in canine and classically start within subcutaneous tissues in this species (Baez et al., 2004). Periodic cases have been described in other domesticated animals, including two cases affecting cattle: a 14-month-old Holando-Argentino cattle with many intra-abdominal masses attached to serosal and peritoneal surfaces (Renner and Idiart, 1990) and an adult cattle (age and breed unknown) with numerous masses inside lymphatic vessels present in the neck, head, and thorax, and on parietal surfaces of the abdomen (Piercy et al., 1994). In our records, liposarcoma was diagnosed in a one year old cow heifer.

Our data showed that adult animals aged above 2 years were more frequently affected than young. SCC was most commonly found in adult or aged animals and there does not seem to be any breed predisposition (Moulton, 1985). Hassanein and Mahmoud (2009) reported that the mean age affected with neoplasms was 1.5 years in females and 2 years in males. 47 Females and 19 males were affected with neoplasms in our findings. In the same line with Hassanein and Mahmoud (2009) who mentioned that the neoplasm was more commonly observed in females $(56.5 \%)$ than males (43.5\%). Number of malignant tumors (41/66) was higher than number of benign tumors in our survey $(25 / 66)$. In contrast to Hassanein and Mahmoud (2009) who mentioned that the 
benign neoplasm was more commonly observed than malignant one.

It was concluded that cattle were more susceptible to tumors than buffaloes and sheep. Adult animals aged above 2 years were more frequently affected than young. Females accounted for a higher percentage of the neoplasms than males. The incidence of epithelial tumors was higher than the mesenchymal tumors. The number of malignant tumors was higher than the number of benign tumors. The most common epithelial tumors were SCC and cutaneous papilloma. The most common SCCs affected eyes. Variable degrees of bovine SCC differentiation were detected.

\section{Acknowledgment}

We would like to appreciate efforts exerted by all staff members of Pathology Department and Department of Surgery, Anesthesiology and Radiology Faculty of Veterinary Medicine, Mansoura University.

\section{Conflict of interest: none}

\section{REFERENCES}

Anderson DE, Badzioch MS. Association between solar radiation and ocular squamous cell carcinoma in cattle. Am J Vet Res. 1991; 52:784- 788

Baez JL, Hendrick MJ, Shofer FS, Goldkamp C, Sorenmo KU. Liposarcomas in dogs: 56 cases (1989-2000). J Am Vet Med Assoc. 2004; 224: 887-891,

Bancroft JD, Gamble M. Theory and Practice of Histological Techniques. 5th Ed; Churchill Livingstone, London, UK, pp. 125-138, 2007.

Baipoledi EK. A case of caprine perineal squamous cell carcinoma in Botswana. J South Afri Vet Assoc. 2001; 72(3): 165-166 (En.).

Dukes TW, Bundza A, Corner AH. Bovine Neoplasms Encountered in Canadian Slaughterhouses: a Summary. Can Vet J. 1982; 23(1): 28-30.

El-Mofty SK, James S, Lewis SK. Cancer of the oral cavity and oropharynx. In: Barnes $L$ (ed) Surgical pathology of the head and neck, vol 1, 3rd edn. Informa Healthcare USA, New York, pp 285-299, 2009.

Fazili MR, Buchoo BA, Darzi MM, Bhattacharya HK. Bovine squamous cell carcinoma at unusual sites: a report of 3 cases. Indian J Vet Surg. 2008; 2:139-140.

Goldschmidt MH, Hendrick MJ. Tumors of the skin and soft tissues. In: Tumors in domestic animals, Meuten DJ editor. 4th edition. Blackwell publishing company, lowa. pp. 45-119, 2002.

Hassanein KMA, Mahmoud AZ. Pathologcal studies on tumor incidence in farm animals. Alex J Vet Med. 2009; 28(1): 105-117.

Hawkins CD, Swan RA, Chapman HM. The epidemiology of squamous cell carcinoma of the perineal region of sheep. Australian Veterinary Journal 57: 455-457 2. Lloyd L C 1961 Epithelial tumours of the skin of sheep: tumours of areas exposed to solar radiation. Br J Cancer. 1981; 15: 780789.

Kennedy PC, Miller RB. The Female Genital System: Pathology of Domestic Animals. Academic Press, New- York, USA. pp: 349-470, 1993.

Kiani K, Dezfoulian O, Sookhthezari A, Jahanzad I, Vaziri S. Acantholytic squamous cell carcinoma in a cow. Comp Clin Pathol. 2010; 19: 397.

Kohlirn EW, Mashadi AG. Squamous cell carcinoma in an Iranian buffalo. Indian Vet J. 2008; 85: 555-556

Lioyd LC. Epithelial tumors of the skin of sheep. Br J Cancer. 1961; 15: 780789.

Marosfoi L, Baba Al, Catoi C. Morphological Study of Bovine Tumors. Bull UASVM, Vet Med. 2009; 66(1):147
Meuten DJ. Tumours of the Haemolymphatic System. Tumours in Domestic Animals. 4th edition. lowa State Press, Ames. pp. 151-156, 2002.

Mosbah E, El-Naggar A. Surgical management of caudal rectal tumors in buffaloes. Res J Dairy Sci. 2012; 1-4.

Moulton JE. Tumours in domestic animals (2nd edn). University of California Press, Berkeley, 1985.

Musal B, Ulutas, P, Aydogan A. Vaginal fibrosarcoma in a cow. Irish Vet J. 2007; 60: 424.

Ozsoy SY, Ozyildiz Z, Güzel M. Clinical, Pathological and Immunohistochemical Findings of Bovine Cutaneous Papillomatosis. Ankara Universitesi Veteriner Fakultesi Dergisi. 2011; 58:161-165.

Patel PA, Modi LC, Vyas SB, Joshi AH, Falguni M. A Rare Case of Dermal melanocytoma in Mehsana Buffaloes. IJAVMS. 2011; 5: 377-378.

Piercy DWT, Furlong SJ, Rudram N. Multicentric liposarcoma in a cow. Vet Rec. 1994; 134: 310-311.

Plummer. Tumors from domesticated animals. Can J Comp Med. 1956; 20(7):239-251

Radostits OM, Blood DC, Gray CC. Veterinary medicine: a textbook of the diseases of cattle, sheep, pigs, goats and horses. (8th edn). Baillière Tindall, London, pp: 556- 557, 1994.

Renner JE, Idiart J. Peritoneal liposarcoma in a heifer. Deutsche Tierarztliche Wochenschrift. 1990; 97: 490-491.

Sharma A, Kumar A, Imran S, Pankaj S, Asrani RK. Ultrasonographic, surgical and histopathological findings of a uterine leiomyoma in a cow. Case Reports Vet Med. 2011

Shruthi PJ, Sujatha K, Srilatha CH, Rayulu VC. Incidence of different tumors in bovines Open Access J Sci. 2018; 2(4):220-222.

Silvestre O, Borzacchiello G, Nava D, lovane G, Russo V, Vecchio D, D'Ausilio F, Gault E A, Campo MS, Paciello O. Bovine papillomavirus type 1 DNA and E5 oncoprotein expression in water buffalo fibropapillomas. Vet Pathol. 2009; 46: 636-641.

Sivaseelan S, Balasubranmaniam GA, Srinivasan $P$, Balachandran $P$, Thangathurai R, Dharmaceelan S. Squamous cell carcinoma of eye in a she buffalo. Tamilnadu J Vet Anim Sci. 2008; 3:117-118.

Somvanshi R. Papillomatosis in buffaloes: a less-known disease. Transbound Emerg Dis 2011; 58: 327-332.

Spradbrow PB, Samuel JL, Kelly WR, Wood AL. Skin cancer and papillomaviruses in cattle. J Comp Path. 1987; 97: 469-478.

Spradbrow PB, Hoffmann D. Bovine ocular squamous cell carcinoma. Vet Bull. 1980; 50:449-459.

Tan MT, Yildirim Y, Sozmen M, Bilge Dagalp S, Yilmaz V, Kirmizigul AH, Gokce E. A Histopathological, Immunohistochemical and Molecular Study of Cutaneous Bovine Papillomatosis. Kafkas Universitesi Veteriner Fakultesi Dergisi. 2012; 18(5):739-744.

Tustin RC, Thornton DJ, McNaughton $\mathrm{H}$. High incidence of squamous cell carcinoma of the vulva in Merino ewes on a South African farm. J South Afri Vet Assoc. 1982; 53: 141-143.

Awadin W, Mosbah E. Histopathology of Tumor and Tumor- Like Lesions in Twelve Female Water Buffaloes. J Vet Sci Med Diagn. 2013, 2:2

Weiss E, Frese K. Tumors of the skin. Bull World Health Org.1974; 50: 79-100.

Weaver AD, Atkinson O, Jean GS, Steiner A. Head and neck surgery. Textbook of bovine surgery and lameness. John Willy and Sons, Ltd. Pp: 90- 117, 2018.

Vandegraaff R. Squamous cell carcinoma of the vulva in merino sheep. Austral Vet J. 1976; 52: 21-23.

Yager JA, Scott DW, Wilcock BP. The skin and appendages. In: Pathology of Domestic Animals, K. V. F. Jubb, P. C.; Kennedy and Palmer, Eds, Academic Press, San Diego, pp: 531-738, 1993 